\title{
Role of digestive protease enzymes and related genes in adaptation to host plant in the polyphagous pest, Spodoptera frugiperda (J.E. Smith)
}

Running head: The effect of digestive physiology on adaptation to host plants in $S$. frugiperda

Muhammad Hafeez ${ }^{1}$, Xiaowei Li $^{1}$, Jinming Zhang ${ }^{1}$, Zhijun Zhang ${ }^{1}$, Jun Huang ${ }^{1}$, Likun Wang ${ }^{1}$, Muhammad Musa $\mathrm{Khan}^{2}$, Sakhawat $\mathrm{Shah}^{3}$, G. Mandela Fernández-Grandon ${ }^{4}$, Yaobin $\mathrm{Lu}^{1 *}$

${ }^{1}$ State Key Laboratory for Managing Biotic and Chemical Threats to the Quality and Safety of Agro-products, Institute of Plant Protection and Microbiology, Zhejiang Academy of Agricultural Sciences, Hangzhou 310021, P. R. China

${ }^{2}$ Key Laboratory of Bio-Pesticide Innovation and Application, Guangdong Province, South China Agricultural University, Guangzhou 510642, China.

${ }^{3}$ Hubei Insect Resources Utilization and Sustainable Pest Management Key Laboratory, College of Plant Science and Technology, Huazhong Agricultural University, Wuhan 430070, Hubei, P. R. China

${ }^{4}$ Natural Resources Institute, University of Greenwich, Chatham Maritime, Kent, ME4 4TB, UK

* Corresponding author.

Professor Yaobin Lu Ph.D.

E-mail address: luybcn@163.com 


\begin{abstract}
The evolutionary success of phytophagous insects depends on their ability and efficiency in exploiting plants as a source of energy for survival. Herbivorous insects largely depend on the efficiency, flexibility and diversity of their digestive physiology and sophistication of their detoxification system to use chemically diverse host plants as a food source. The fall armyworm (FAW), Spodoptera frugiperda (J.E. Smith), is a polyphagous pest of many commercially important crops. To increase understanding of the capability of this insect pest toward adaptation to host plant mechanisms, we evaluated the impact of primary (corn) and alternate (rice, after 11th generation) host plants on the gut digestive enzymatic activity and expression profile of related genes. Results indicated that the total protease and class-specific trypsin and chymotrypsin-like protease activity of $S$. frugiperda was significantly different on different host plant treatments. The profile of class-specific protease inhibition greatly differed in the midgut of $S$. frugiperda larvae treatments compared to the treatments without inhibitors. Similarly, the single and cumulative enzyme specific inhibitors, TLCK, TPCK and E-64, significantly increased the larval mortality and reduced the larval growth/mass on different plant treatments. Furthermore, the results of quantitative RT-PCR revealed an increase in transcription of two trypsin and one chymotrypsin gene, suggesting its role in host plant adaptation. Knockdown of two SfTry-3, SfTry-7 and one Sfchym-9 gene significantly reduced the mRNA expression levels of the trypsin genes. This related to an increased mortality observed in treatments compared to the dsRED control. This result indicates possible role of the $S$. frugiperda gut digestive enzymes and related genes in host plant adaptation.
\end{abstract}

Keywords: Genes expression; S. frugiperda; digestive enzymes; host plant adaptation; RNAi 


\section{Introduction}

Diversity of phytophagous diets in insects are largely influenced by host plant chemistry evolved to deter herbivory and reciprocal coevolution of biochemical and behavioral mechanisms in the insect to detoxify, or otherwise avoid, plant defensive compounds (Renwick, 1994; Schoonhoven, Jermy and van Loon, 1998). Phenotypic flexibility of the host plant and related herbivores plays a key role in the interactions and survivorship of individuals at each trophic level (Tilmon, 2008). Each plant has a specific phytochemical profile consisting of both primary and secondary metabolites that form the basis of host selection and discrimination by an insect (Del Campo et al., 2001). For example, maize and rice plants contain similar nutritive values (Butterworth, 1963; Sarmini and Premaratne, 2017) but with distinct phytochemical profiles (Nawaz et al., 2018; Wang et al., 2018). These chemicals notify the foraging insects about the suitability of a plant as a food source (Renwick, 1994; Schoonhoven, Jermy and van Loon, 1998), determine an insect's food choice and its subsequent performance (Chen et al., 2019). Through this selection process, phytochemicals and nutritional content plays a critical role in in host-plant adaptation (Fischer, Kogan and Paxton, 1990; Renwick, 1994; Foss and Rieske, 2003). These iterative cycles of plant adaptation and herbivore counter adaptation provide a rich opportunity to understand the basic host plant adaptation mechanisms.

Due to adaptation of host plants, insects largely depend on a wide spectrum of digestive enzymes and a sophisticated detoxification system to use chemically diverse host plants as food sources (Ehrlich and Raven, 1964; Berenbaum and Neal, 1985; Veenstra, Pashley and Ottea, 1995; Zalucki, Clarke and Malcolm, 2002; Borzoui, Naseri and Rahimi Namin, 2015). In most cases, digestive proteases are the most abundant and essential protease enzymes required for metabolism and digestion. These are spatially and temporally expressed in the midgut of herbivorous insects 
during foraging (Zhu-Salzman and Zeng, 2015b; Cantón and Bonning, 2020). A total of 86 and 113 digestive serine proteases in Corn and Rice strains, respectively, were identified in the $S$. frugiperda genome (Gouin et al., 2017). Among these proteases, serine proteases (SPs) carry out around 95\% of digestive activity (protein digestion) in insects (Herrero et al., 2005; Srinivasan, Giri and Gupta, 2006). These are produced by the midgut epithelial cells and secreted into the lumen (Dunse et al., 2010). Digestive serine proteases, such as of trypsin and chymotrypsin, are predominant in the gut of lepidopteran insects having the same mechanistic class but different substrate specificity (Terra and Ferreira, 1994 ). Trypsins are specific for hydrolysis of peptide bonds adjacent to basic amino acids arginine or lysine, while chymotrypsins are specific for aromatic or bulky non-polar amino acids such as tryptophan, phenylalanine, or tyrosine (Gatehouse et al., 1998; Lin et al., 2015). Digestive flexibility and expression of related genes to plant chemical toxicants in a number of insect species have been previously documented as an adaptive mechanism to noxious chemical-containing host plants. For example, a number of insect species including Busseola fusca (Juma, Le Ru and Calatayud, 2019), Oedaleus asiaticus (Huang et al., 2017), cabbage looper (Rivera-Vega et al., 2017), Spodoptera frugiperda (Brioschi et al., 2007), Nezara viridula (Cantón and Bonning, 2020) and Bombyx mori (Liu et al., 2017) have been reported to modify the activity of their gut enzymes and related genes expression in response to the chemical composition of the food source (Singh et al., 2020). In response to physical and chemical plant barriers, the herbivores develop physiological, morphological and behavioral adaptations that directly affect their ability to exploit specific hosts.

The fall armyworm (FAW), Spodoptera frugiperda (J.E. Smith), is a polyphagous pest of many important crops. It is identified as having two sympatric strains that show dissimilar host preferences under field conditions. The 'corn strain' predominantly feeds on corn (Zea), sorghum 
and cotton (Gossypium), while the 'rice strain' shows preference for rice (Oryza sativa) and some forage grasses, such as Bermuda grass (Del Campo et al., 2001; Machado et al., 2008; Assefa, 2019). The polyphagy of S. frugiperda larvae can be associated with possible plastic biochemical, physiological, or evolutionary mechanisms that permit the insect to challenge a variety of chemical complexities posed by diverse food plants. The pest has spread rapidly around the world, amassing substantial crop losses in each new location it has been found (Goergen et al., 2016). In recent years, FAW continued to spread in West and Central Africa and has recently been found in Indonesia and Southwest China (Southwest Yunnan province) (Goergen et al., 2016; Ginting et al., 2020; Li et al., 2020). Application of synthetic pesticides and planting transgenic (Bt) corn have been considered the most effective, and therefore remain the primary, strategies for controlling S. frugiperda (Yu, Nguyen and Abo-Elghar, 2003; Carvalho et al., 2013). However, excessive dependence on these methods has had implications for the ecosystem, posing a serious threat to non-target organisms, including beneficial insects, and leading to selection for high levels of resistance within FAW populations (Vanbergen et al., 2013; Kumar et al., 2016).

One promising technology is the application of RNA interference (RNAi), using gene silencing based on the conserved biological defence response at the cellular level triggered by double-stranded RNA (dsRNA). This approach could form the next generation of insect-resistant, genetically modified crops (Mello and Conte, 2004; Zhang et al., 2017; Chen et al., 2019; Bennett et al., 2020). When double strand-RNA (dsRNA) is ingested by insects feeding on transgenic plants, artificial diet or by droplet-feeding, it can knockdown genes via the RNAi pathway leading to a decrease in the growth or mortality of the target pests (Lim et al., 2016; Zhang et al., 2017; Hafeez et al., 2019; Shah et al., 2020). In previous studies, downregulation of CTP (chymotrypsins)-like enzymes and SfT6 (serine protease gene) were documented in lepidopteran 
insects by dsRNA feeding approach (Rodríguez-Cabrera et al., 2010; Guan, Li and Miao, 2017). However, to develop the technology for application, it is necessary to understand the host plant adaptation mechanisms as well as identifying target genes involved in the digestive system of insects against host plant chemical defences.

Previous work (Acevedo et al., 2018) has demonstrated the effect of FAW intraspecific salivary changes on induced plant defence responses and changes in the expression range of trypsin and chymotrypsin. In this study, for the first-time to the author's knowledge, enzymes directly involved in the adaptation to a host plant were characterised from the gut of S. frugiperda larvae. The host plant adaptation mechanism in fall armyworm reared on preferred and non-preferred host plants for 11 generations was examined with the effects of the preferred and non-preferred host plant diet on the digestive enzyme's activities in the midgut of S. frugiperda. We evaluated the mechanism of larval midgut digestive enzymes on larval growth and mortality by comparing the effects of inhibitors with specificity towards both trypsin and chymotrypsin. Changes in the expression pattern of trypsin and chymotrypsin-encoding genes were also evaluated. Lastly, the functional analysis of highly expressed genes was studied using RNAi to assess whether these genes play a functional role in adaptation mechanism to host plants. 


\section{Material and Methods}

\section{Insect collection}

Field populations of Spodoptera frugiperda were established from 200 larval instars of various stages collected from two different corn fields in Ping Hu, Zhejiang Province during August 2019. Larvae were reared on corn plants in a climate control chamber at $25 \pm 2{ }^{\circ} \mathrm{C}$ with a $14: 10 \mathrm{~h}$ light: dark photoperiod in the Institute of Plant protection and Microbiology, Zhejiang Academy of Agricultural Sciences Hangzhou, China. Following pupation, newly emerged adults were sexed with mating pairs placed together in cages and provided with $10 \%$ honey solution as a food source. The population was reared through one generation to establish the colony before being used in host selection experiments. Later instars and adults were examined to confirm species based on diagnostic taxonomic characters and by using the strain-specific Tpi molecular marker following (Nagoshi et al., 2019).

\section{Reagents}

The protease substrates azocasein, $\mathrm{Na}$-Benzoyl-D, L-arginine 4-nitroanilide hydrochloride (BApNA), N-Succinyl-Ala-Ala-Pro-Phe p-nitroanilide (SAAPFpNA), were purchased from Sigma-Aldrich. The inhibitors Phenylmethylsulfonyl fluoride (PMSF), Na-Tosyl-L-lysine chloromethyl ketone hydrochloride (TLCK), Na -Tosyl-L-phenyl alanine chloromethyl ketone (TPCK), E-64, trichloric acid were also purchased from Sigma-Aldrich.

\section{Host plants}

The two host crops used were commercially used varieties of sweetcorn (Zhetaitian928) Zea mays, and rice (Liangyou-887) Oryza sativa. Seeds were purchased from China and planted in plastic pots $(10 \mathrm{~cm}$ in diameter and $12 \mathrm{~cm}$ in height) filled with a potting medium of peat moss: 
vermiculite. These were grown in an experimental greenhouse at Zhejiang Academy of Agricultural Sciences. Plants aged 15-20 days were used for all the experiments.

\section{Rearing and host plant selection}

To avoid any homogenization effect, two combinations were made, one of the corn population larvae reared on corn plants for 11 generations, referred to hereafter as Corn population and the other with larvae from the same corn population reared on rice plants for 11 generations, referred to hereafter as the Rice population. For both combinations, at least 300 larvae from the field collected population (already reared on corn for one generation) were placed individually in separate cages containing one of the two host plants; corn for Corn population and rice for Rice population. Both colonies were reared in climate chambers at $27 \pm 2{ }^{\circ} \mathrm{C}, 70-75 \%$ R.H. and L14:D10 photoperiod until adult emergence. Each population was assigned a code denoting the host plant of each form i.e., corn strain reared on corn plants (Corn) or corn strain reared on rice plants (Rice) (Fig 1), the year of collection, and the region. From neonate to third-instar larvae, 15-day-old seedling plants of rice or corn were provided, while 20-day-old rice or corn were provided for fourth and fifth-instar larvae. Populations were observed daily. Approximately, 50 adults were used from each population to establish the host-specific strain colony in separate mating cages $(30 \mathrm{~cm}$ high, $10 \mathrm{~cm}$ in diameter, cylindrical polyethylene-terephthalate cages with nylon mesh cloth). Strips of paper were provided in the cages allowing females to rest and to lay eggs. Honey solution (10\%) was administered via a saturated cotton plug which was renewed daily. Cages were checked daily for oviposition and adult mortality. To minimise the loss of genetic variability, once females started to lay egg masses, 15 egg masses from each cage were collected and deposited in glass tubes ( $12 \mathrm{~cm}$ high, 1.5 diameter). Once emerged, 10 neonate larvae from each of the egg masses were placed individually in small cages already containing primary 
and alternate host plants. Feeding choice, larval growth, survival rate, pupal weight, oviposition behaviour of female on primary (corn) and alternate (rice) host plants (from G1-G11) were noted (unpublished data).

\section{The effect of host plant on adaptation mechanism of S. frugiperda}

After 11 generations reared on corn or rice plants, the following five treatments and control were applied; (i) Corn population (Corn), (ii) Corn to rice population (Corn-R), (iii) Rice population (Rice), (iv) Rice to corn population (Rice-C) and (v) control respectively. A total of 60 secondinstar larvae from the corn population (Corn) were transferred to rice plants for three days. This treatment was referred to as Corn-R indicating its transfer to rice from corn. This was done as three replicates with 20 larvae in each replicate. Similarly, a total of 60 second-instar larvae from the rice population (Rice) were transferred to corn plants for three days. This treatment was referred to as Rice-C, indicating its transfer from rice to corn. Again, this was conducted as three replicates. Additionally, 60 second-instar larvae were transferred individually in a small transparent petridishes with a moist cotton plug with dd water to form the control group.

\section{Sample collection for enzyme activity and RNA extraction}

After $72 \mathrm{~h}$ feeding on the following host plant treatments (i) Corn population (Corn), (ii) Corn to rice population (Corn-R), (iii) Rice population (Rice), (iv) Rice to corn population (Rice-C), larval midguts were prepared according to Rodrigues Macedo et al. (2003). Larvae from each treatment were cold immobilized and their midguts dissected in 0.1 M PBS, pH 7.4. For each biological replicate. Approximately 9 midguts from larvae were dissected and pooled for enzymatic activity assays. Midguts collected for RNA and protein extraction were frozen in liquid nitrogen and stored at $-80{ }^{\circ} \mathrm{C}$ until RNA and protein extraction. 


\section{Measurement of enzymatic activity}

Class-specific protease activity (trypsin and chymotrypsin activity) was measured according to the methodology described by de Oliveira et al. (2013) with slight modification. A $1 \mathrm{mM}$ solution of each synthetic substrate (BApNA and SAAPFpNA) was prepared by dissolving substrate powders in $10 \%$ of DMSO and slowly adding $0.1 \mathrm{M}$ acetate buffer solution with $\mathrm{pH}$ 5.0. Similarly, total midgut extract $(50 \mathrm{mg}$ ) was mixed in $20 \mu 1$ solution of acetate buffer. The reaction mixtures were incubated for $30 \mathrm{~min}$ at $37^{\circ} \mathrm{C}$, followed by the addition of $100 \mu \mathrm{l}$ of substrate solution and incubated again at $37^{\circ} \mathrm{C}$. To stop the reaction, $100 \mu 1$ of $30 \%$ acetic acid was added. A total of $200 \mu 1$ from each reaction was added in 96-well plates and the absorbance was measured at $410 \mathrm{~nm}$ using an iD7 SpectraMax 190 microplate reader (Molecular Devices, San Jose, CA, United States). The units in the enzyme activity assays were defined as the change of 0.1 of absorbance/minute/mg/protein.

Proteolytic activity of midgut extracts was determined by degradation of azocasein as described previously Lomate et al (2016) and Lomate \& Bonning (2016) with optimization following Cantón et al (2020) and Cantón \& Bonning (2020). For each treatment (Corn, Rice, Corn$\mathrm{R}$, Rice-C), a total of $50 \mathrm{mg}$ of midgut extract was added in a reaction tube and incubated for 30 $\min$ at $37^{\circ} \mathrm{C}$ with or without the following inhibitors: $100 \mathrm{mM}$ TLCK, $10 \mathrm{mM}$ E-64 and $100 \mathrm{mM}$ TPCK. The reaction was made up to a total volume of $10 \mu \mathrm{l}$ in $0.1 \mathrm{M}$ acetate buffer with $\mathrm{pH}$ 5.0. After incubation, $200 \mu \mathrm{l}$ of a $1 \%$ azocasein solution in $0.1 \mathrm{M}$ acetate buffer $\mathrm{pH} 5.0$ was added. The tubes were then incubated at $37^{\circ} \mathrm{C}$ for $2 \mathrm{~h} .300 \mu \mathrm{l}$ of chilled $5 \%$ trichloroacetic acid was added to the tubes to stop the reactions before being centrifuged at $10000 \mathrm{~g}$ for $10 \mathrm{~min}$ at $4^{\circ} \mathrm{C} .150 \mu \mathrm{l}$ of 1 $\mathrm{M} \mathrm{NaOH}$ was added to neutralize $150 \mu \mathrm{l}$ of supernatant in a $96-$ well clear bottom plate. The 
absorbance was measure at $450 \mathrm{~nm}$ using an iD7 SpectraMax 190 microplate reader (Molecular Devices, San Jose, CA, United States).

\section{Assessment of single and cumulative effects of enzyme-specific inhibitors on larval growth}

For the evaluation of enzyme-specific inhibitors on larval growth of S. frugiperda, we selected the single concentrations as well as combined concentrations of enzyme-specific synthetic inhibitors like TLCK, TPCK and E-64 for trypsin, chymotrypsin and serine-protease, respectively. Enzymespecific inhibitors were dissolved in dimethyl sulfoxide (DMSO) before being added into the diets. All enzyme-specific inhibitors contained a final concentration of 1\% DMSO and were thoroughly mixed with the pinto bean-based artificial diet and transferred to small plastic cups before the solidification of the agar medium $\left(\sim 40-45^{\circ} \mathrm{C}\right)$. The diet for the control treatment was prepared using the same method but with an equal volume of DMSO without enzyme-specific inhibitors supplementation. A total of 150 second-instar larvae for each treatment from corn population on corn plant (Corn) and 150 second instar larvae for each treatment from rice population on rice plant (Rice) were transferred to artificial diet supplemented with enzyme-specific inhibitors. Furthermore, 150 second-instar larvae from corn and rice populations were transferred individually into small transparent petri-dishes complemented with an equal volume of DMSO as a control. After $24 \mathrm{~h}$ feeding on diet supplemented with enzyme-specific inhibitors and control as mentioned above, a total of 60 larvae for each treatment (completed as three replicates of 20 larvae) were transferred onto respective host plants treatments corn (Corn) and Corn to rice (Corn-R) or rice (Rice) and Rice to corn (Rice-C). Similar method was used for control fed on diet supplemented with DMSO. Larval mortality and weight were noted after $72 \mathrm{~h}$ feeding on their respective treatments to assess the single and cumulative effects of enzyme-specific inhibitors on larval growth and pupal weight. 


\section{Expression of trypsin and chymotrypsin genes by qRT-PCR}

Total RNA was extracted from frozen midguts as described above using $1 \mathrm{~mL}$ of TRIzol ${ }^{\mathrm{TM}}$ (Invitrogen). The cDNAs Synthesis from total RNA was primed by oligo d(T) using TransScript® One-Step gDNA Removal and cDNA Synthesis SuperMix. The reaction mixture of $20 \mu 1$ consisted of Anchored Oligo(dT)18 Primer $(0.5 \mu \mathrm{g} / \mu \mathrm{l}) 1 \mu \mathrm{l}, 2 \times \mathrm{TS}$ Reaction Mix 10 $\mu \mathrm{l}, 1 \mu \mathrm{l}$ RNA, TransScript ${ }^{\circledR}$ RT/RI Enzyme Mix $1 \mu 1$, gDNA Remover $1 \mu$ and RNase-free Water $5 \mu 1$ according to the manufacturer's recommendations. The cDNA was diluted in a work solution and $4 \mu \mathrm{L}$ was used in qRT-PCR. The primers were designed using Premier 5 software, the sequences of the primers used for candidate genes are listed in Table 1. The RT-qPCR analysis was performed with three biological (12 larvae in each replicate) and three technical replicates in each treatment including the control using a CFX96 ${ }^{\mathrm{TM}}$ Real-Time PCR Detection System (Bio-Rad, Hercules, CA, USA) with SsoFast EvoGreen ${ }^{\circledR}$ SuperMix (BIO RAD, USA). The RT-qPCR mixture consisted of $20 \mu 1$ of total volume containing $10 \mu \mathrm{l}$ of $2 \times$ PCR mixture (Sangdon Biotech, China), $0.5 \mu \mathrm{l}$ of each sense and antisense primers $(10 \mu \mathrm{M}), 3 \mu \mathrm{l}$ of cDNA template, and $6 \mu \mathrm{l}$ of dd $\mathrm{H}_{2} \mathrm{O}$. The protocol for qRT-PCR was used as follows: $95^{\circ} \mathrm{C}$ for $30 \mathrm{~s}$, followed by 40 cycles at $95^{\circ} \mathrm{C}$ for $5 \mathrm{~s}$ and at $60^{\circ} \mathrm{C}$ for $30 \mathrm{~s}$. GAPDH (GenBank: KC262638.1) S30 (AF400225.1) were used as the internal control gene for normalisation. All reactions were run in triplicate and fold changes were calculated using ${ }^{2-} \Delta \Delta \mathrm{CT}$ method developed by Livak and Schmittgen (2001).

\section{Preparation, quantification and purification of dsRNA}

For dsRNA synthesis, the SfTrypsin-3, SfTrypsin-7, and Sfchym-9 with fragment sizes 789 bp, 731 bp and 789 bp, respectively, were amplified by PCR and dsRED from the PCR template amplified from the PEGM T-easy plasmid. The primers used for the SfTrypsin-3, SfTrypsin-7, Sfchym-9 and dsRED amplifications were designed to add the T7 polymerase promoter sequence 
to the 5 ends of each strand (Table 1). Similarly, the dsRED as a control was prepared using the same method by designing the two pairs of primer (T7RED-F and RED-R, RED-F and T7REDR) (Table 1). The dsRED reference template was provided by the Dr Lu laboratory (Huazhong Agricultural University, Wuhan, China). The dsSfTrypsin-3, dsSfTrypsin-7, dsSfchym-9 and dsRED were prepared from the purified PCR-generated templates according to the instructions and method provided with the T7 RiboMax Express RNAi System kit (Promega, Madison, WI, USA). The dsRNA was then purified using MEGA clearTM Kit (Ambion). The resulting dsRNA from all genes, including the control gene, were quantified by NanoDrop® spectrophotometer (Thermo Fisher, MA, USA) and integrity was analysed by agarose gel electrophoresis before being stored at $-80^{\circ} \mathrm{C}$ prior to use.

\section{Feeding bioassays}

To prevent the damage to S. frugiperda larvae, we used a droplet-feeding method for RNAi as previously described in the literature (X. Wang et al., 2018; Hafeez et al., 2019). For RNAi feeding bioassays, firstly the dsRNA was dissolved in DEPC-treated water. The third-instar larvae from corn and rice populations were placed individually in sterilized 24-orifice tissue culture plates and starved for $6 \mathrm{~h}$. The dsRNA solution $(500 \mu \mathrm{g} / \mu \mathrm{l})$ was configured by dissolving in DEPC treated water. The starved larvae were placed individually in sterilized 24-orifice tissue culture plate containing one gram of artificial diet in each well. A single drop $0.5 \mu \mathrm{l}(500 \mu \mathrm{g} / \mu \mathrm{l})$ of dsRNA solution was placed near each larval mouth using a $2 \mu \mathrm{l}$ pipette (www.eppendorf.com). After $24 \mathrm{~h}$ feeding on artificial diet containing dsRNAs, the larvae were transferred to different host plant treatments. A total of sixty S. frugiperda larvae for each independent plant treatment (in three replicates of 20 larvae each) were transferred individually onto a 12-day old seedling of corn (Corn), (Corn-R), or rice (Rice) and (Rice-C). For mortality analysis, the mortality and larval mass 
were recorded at $72 \mathrm{~h}$ after feeding on different treatments. All experiments were conducted in triplicate.

\section{Quantitative RT-PCR analysis of trypsin and chymotrypsin expression after RNAi}

The midguts were dissected from larvae fed on different host plant treatments after the ingestion of dsSfTrypsin-3, dsSfTrypsin-7, dsSfchym-9 and dsRED as a control. Total RNA was extracted and the cDNAs was synthesized from total RNA as described above. The primers were designed using Premier 5 software, the sequences of the primers used for candidate genes are listed in Table 1. qRT-PCR was performed using SsoFast ${ }^{\mathrm{TM}}$ EvaGreenH Supermix (Bio-Rad) according to the manufacturer's instructions on CFX96 ${ }^{\mathrm{TM}}$ Real-Time PCR Detection System (Bio-Rad, Hercules, CA, USA). GAPDH (GenBank: KC262638.1) was used as the internal control gene for normalisation. The assays were performed with three biological replicates (12 larvae in each replicate) and three technical replicates in each treatment including a control.

\section{Statistical analysis}

The difference in mean values of the treatments was calculated using one-way analysis of variance (ANOVA) and the important variations among the treatments were determined with a post-hoc Tukey test for multiple comparisons, the p-value of $<0.05$ was considered significant. All statistical analyses were conducted using SPSS software (version 19.0, SPSS Inc., Chicago, IL, USA). 


\section{Results}

\section{Effects of host plants on total and class-specific enzymatic activity of $S$. frugiperda}

The total enzyme activity and class-specific trypsin and chymotrypsin activity in the $S$. frugiperda gut was assayed for individuals feeding on different host plant treatments. Substrates used were azocasein, N $\alpha$-Benzoyl-L-arginine 4-nitroanilide hydrochloride and SAAPFpNA. Enzyme activity with azocasein substrate was greatest for individuals fed on rice for 11 generations (Fig. 2A). The second highest levels of enzyme activity were seen in the treatment in which larvae were transferred from corn to rice (Corn-R) for $72 \mathrm{~h}$. All treatments, including the original population raised only on corn, showed elevated levels of activity compared to the other treatments. Furthermore, the class-specific trypsin-like protease activity in the midgut was also highest in the 'Rice' treatment, however, activity at other levels was different, with larvae switching from rice to corn for $72 \mathrm{~h}$ (Rice-C) showing the second highest activity levels (Fig. 2B). Again, all treatment groups showed different elevated activity. For the class-specific chymotrypsin-like protease activity, it was this Rice-C treatment that showed significantly higher activity than all other treatments (Fig. 2C) with Corn-R showing the lowest level of activity of the treatments. Taken together, the higher number of total enzyme and the class-specific trypsin and chymotrypsin-like protease activity detected in the midgut feeding on different treatments indicates host plant adaptation in $S$. frugiperda.

\section{Effects of synthetic inhibitors on an enzymatic activity of $S$. frugiperda}

The profile of class-specific protease inhibition greatly differed in the midgut of $S$. frugiperda larvae for different treatments (Fig. 3). Results indicate that E-64 inhibitor significantly reduced the activity of serine proteases while no significant difference was found between TLCK and TPCK when larvae fed on Corn plants (Fig. 3). Similarly, the class-specific inhibitors TLCK and 
TPCK significantly inhibited the gut trypsin and chymotrypsin activity as compared to serine proteases in Corn-R treatment respectively (Fig. 3). Furthermore, drastically reduced activity of chymotrypsin with TPCK followed by trypsin with TLCK and serine protease with E-64 inhibitor was observed in Corn- $\mathrm{R}$ treatment. Similar trend was observed in Rice-C treatment with significantly reduced activity of serine protease with E-64 inhibition followed by chymotrypsin with TPCK and trypsin with TLCK (Fig. 3). It was found that Corn, Corn-R and Rice-C were all equally inhibited with Rice treatment less severely affected (Fig. 3).

Assessment of single and cumulative effects of enzyme-specific inhibitors on larval mortality

To demarcate the effect of specific protease inhibitors, the single and combined effect of classspecific protease inhibitors was evaluated on the larval mortality for groups feeding on different treatments (Fig. 4A). Higher mortality was observed when larvae fed on Corn plants for $72 \mathrm{~h}$ prior to exposure to TLCK, TPCK and E-64 supplemented diet for $24 \mathrm{~h}$ while no difference in mortality was observed between the E-64 inhibitors and those fed on plants without any inhibitors. Similarly, significantly higher mortality was observed when larvae fed on Rice and Corn-R plants for $72 \mathrm{~h}$ prior to exposure to TLCK, TPCK and E-64 supplemented diet for $24 \mathrm{~h}$ as compared to plants without any inhibitors. Interestingly, significantly higher mortality was observed when larvae had prior exposure to diet supplemented with TLCK for $24 \mathrm{~h}$ followed by Rice or Corn-R diets compared to another treatments and plants without any inhibitors for $72 \mathrm{~h}$ (Fig. 4A). Furthermore, cumulative effects of enzyme-specific inhibitors TLCK+TPCK, TLCK+E-64, TPCK+E-64 and TLCK+TPCK+E-64 on larval mortality for the different treatments were evaluated and compared to treatments without any inhibitors for $72 \mathrm{~h}$ (Fig. 4B). 


\section{Assessment of single and cumulative effects of enzyme-specific inhibitors on larval growth.}

Differences in larval growth was assessed for S. frugiperda reared on the two host plants prior to feeding on single and cumulative enzyme-specific inhibitors (Fig. 5). In each trial, all treatments were found to show significantly reduced growth compared to treatments without inhibitors. Exposure to enzyme-specific inhibitors TPCK and TLCK for $24 \mathrm{~h}$ followed by Corn diet for $72 \mathrm{~h}$ led to significantly reduced larval mass compared to E-64 inhibitor and corn plants without inhibitors. No significant differences were observed between TPCK and TLCK or E-64 inhibitor and corn plants without inhibitors after $72 \mathrm{~h}$. Similarly, the enzyme-specific inhibitor TPCK, TLCK and E-64 significantly reduced the mass of S. frugiperda larvae when fed on Rice plants as compared to Rice plants without inhibitors for $72 \mathrm{~h}$ (Fig. 5A). A similar trend was observed in the larval mass of individuals with prior exposure to enzyme-specific inhibitor TPCK, TLCK and E64 for $24 \mathrm{~h}$ followed by fed on Corn-R and Rice-C plants for $72 \mathrm{~h}$ as compared to the plants without inhibitors, while there was no difference observed between plants with E-64 inhibitor and without inhibitors (Fig. 5A). The cumulative effect of enzyme-specific inhibitors TLCK+TPCK, TLCK+E-64, TPCK+E-64 and TLCK+TPCK+E-64 led to significant reductions in growth after feeding on different plant treatments for $72 \mathrm{~h}$, with Corn-R treatment consistently showing the greatest inhibition to growth when compared to plants without inhibitors (Fig. 5B).

\section{Effect of host plant on expression pattern of trypsin and chymotrypsin-related genes}

Once the adaptive response of host plant on the modifications in enzymatic activity was established, we analysed the expression pattern of trypsin and chymotrypsin-like protease genes in S. frugiperda. Through qRT-PCR analyses, seven trypsin (SfTry-2, SfTry-3, SfTry-4, SfTry-5, SfTry-7, SfTry-8 and SfTry-9) and six chymotrypsin (Sfchym1, Sfchym-2, Sfchym-3, Sfchym-5, Sfchym-7, Sfchym-9) genes were studied (Fig. 6). Through qRT-PCR it was shown that the two 
trypsin genes displayed distinct patterns when fed on different plant treatments. The trypsin gene SfTry-3 showed an increase in transcription level when fed on Corn and Rice-C treatments, whereas, the transcription level of SfTry-7 gene showed the strongest expression when larvae fed on Rice and Corn-R treatments (Fig. 6A). Only one chymotrypsin gene, Sfchym-9, showed a significant increase in transcription level when larvae fed on Corn and Rice-C treatments as compared to other treatments and control (Fig. 6B).

\section{Effect of Silencing by dsRNA}

To evaluate whether knockdown of dsSfTry-3, dsSfTry-7 and dsSfChym-9 genes have an effect on the midgut and host plants adaptation in S. frugiperda, RNAi-mediated down-regulation effect of these genes was evaluated using third-instar larvae exposed to different host plants. It was shown that dsRNA via droplet feeding following feeding on Corn, Corn-R Rice, and Rice-C led to significant down-regulation in the mRNA expression levels of dsSfTry-3 (Fig 7A), dsSfTry-7 (Fig 7A) and dsSfChym-9 as compared to the dsRED control (Fig. 7B).

\section{Effects of dsSftry-3, dsSftry-7 and dsSfchym-9 on larval mortality and mass}

The knockdown of dsSfTry-3 and dsSfTry-7 genes were shown to significantly increase mortality of S. frugiperda larvae when fed on Rice, Corn-R and Rice-Corn as compared to dsRED fed larvae on Rice, Corn-R and Rice-Corn as control treatments. While no significant knockdown effect of dsSfChym-9 on the larval mortality was observed when fed on Rice, Corn-R and Rice-Corn as compared to dsRED fed larvae on plans as control treatments respectively (Fig. 8A). Similarly, lower larval weight was observed after $72 \mathrm{~h}$ following exposure to dsRNA of dsSfTry-3 and dsSfTry-7 genes as compared to dsRED fed larvae on different plant treatments as a control (Fig. 8B). A similar trend was noted in groups exposed to dsRNA of dsSfChym-9 gene, with significantly lowered larval weight but without a consistent impact on mortality (Fig. 8). 



\section{Discussion}

Insect herbivores are engaged in an intimate relationship with their host plants. For S. frugiperda, the host plant provides many aspects essential for the insect's success such as food, a mating site, oviposition site and a suitable habitat throughout many of their life stages. This relationship involves adaptation of the insect to cope with the plant phenology, specific nutritional components and chemical/physical defences. As a result, insect herbivores tend to adapt to feeding on a limited number of host plants, related by their biochemical configuration (Futuyma and Agrawal, 2009; Forister et al., 2012; Becerra, 2015). Despite the threat this invasive pest poses to food security, fundamental knowledge of $S$. frugiperda physiological adaptation mechanisms are limited, with no comprehensive investigation of digestive enzymes yet. In this study, we evaluated if, and how, the feeding behaviour and digestive physiology plays a role in host plant adaptation mechanisms in S. frugiperda.

Following the adaptation of a specific host plant, phytophagous insects often depend on the effectiveness of that digestive physiology to feed on chemically diverse hosts as a food source (Zalucki, Clarke and Malcolm, 2002; Wang et al., 2006; Borzoui, Naseri and Rahimi Namin, 2015). While able to feed on a variety of plants, this process of adaptation means they retain 'preferences' of hosts on which they show more successful development. Significant differences were detected by digestive enzyme assays of midgut tissue in total enzyme activity and classspecific protease profiles from $S$. frugiperda larvae maintained on rice plants or corn plants over 11 generations. These results support previous work (Golikhajeh, Naseri and Razmjou, 2017) which proposed that digestive protease and amylase activity of S. exigua larvae was significantly increased by feeding on different host plant cultivars. Similarly, previous studies have demonstrated that the genetic adaptations of host plants played out over evolutionary time scales, 
with insect herbivores regulating their feeding behaviour and midgut digestive physiology to the nutritional landscape of available food sources. Herbivores may alter the plants defence systems by inducing the expression of digestive and detoxification enzymes in gut tissues (Dermauw et al., 2013; Herde and Howe, 2014; Golikhajeh, Naseri and Razmjou, 2017; Acevedo et al., 2018; Juma, Le $\mathrm{Ru}$ and Calatayud, 2019), however, adaptation to plant defences is not restricted to digestive enzyme activity and other metabolic processes such as detoxification, stress response, and immunity pathways can also be involved (Huang et al., 2017). Our data indicate that the classspecific activity of chymotrypsin, trypsin and serine proteases were inhibited by TPCK, TLCK and E-64 inhibitors after feeding by S. frugiperda larvae in Corn, Corn-R, Rice and Rice-C treatments. This is consistent with inhibited enzymatic, class-specific activity of chymotrypsin, trypsin and serine proteases in other insects species (Saadati and Bandani, 2011; Lomate and Hivrale, 2013; Cantón and Bonning, 2020). Previously studies have shown that protease inhibitors are used to disrupt the digestive process and control lepidopteran pests, however, consequently lead to the elevation of other protease types, highlighting the flexibility of insect digestion physiology (Zhu-Salzman and Zeng, 2015a; Spit et al., 2016).

The mortality of $S$. frugiperda larvae was significantly increased by the presence of classspecific protease inhibitors in their diet for $24 \mathrm{~h}$ prior to feeding on specific host plants for $72 \mathrm{~h}$ compared to the control treatment. Conversely, a lower mortality rate was observed in the presence of serine protease inhibitors E-64. A combination of TPCK, TLCK and E-64 (each at 2\% concentration) increased mortality rate for insects after feeding on specific host plants, suggesting that trypsin and chymotrypsin play an important role for host plant adaptation in S. frugiperda. Similar results have been demonstrated by Saadati and Bandani (2011) who reported a significantly higher mortality rate of sunn pests, Eurygaster integriceps, when provided with a 
combination of TPCK and SBTI, both at $4 \%$ of dietary protein. Interestingly, each inhibitor individually and jointly caused significant mortality, but did not produce $100 \%$ mortality, indicating that $S$. frugiperda could complete its growth with one of the proteases. Furthermore, the average larval weight of $S$. frugiperda was significantly reduced by the presence of class-specific protease inhibitors in their diet for $24 \mathrm{~h}$ prior to feeding on specific host plants for $48 \mathrm{~h}$ when compared to control treatment. This trend was also observed for the average larval weight using a combination of TPCK, TLCK and E-64 each at $2 \%$ concentration after feeding on specific host plants. Similar results have also been reported previously for insects reared exclusively on diets containing enzyme inhibitors and when feeding on their host plants (Saadati and Bandani, 2011; de Oliveira et al., 2013; Borzoui, Naseri and Rahimi Namin, 2015; Cantón and Bonning, 2020).

The effect of host plants on the diversity of FAW strains has long been recognised (Groot et al., 2010). However, the use of preferred and alternate host plants and the genetic mechanisms of adaptation in the speciation process of FAW are still unknown. Our findings support that some genes with important functions can account for the adaptation to one host plant but not others (Beaumont and Balding, 2004). We investigated the mRNA expression level of different trypsin and chymotrypsin genes as reported by de Oliveira et al. (2013) to determine how different host plants might affect lineage distinction in an important polyphagous insect pest. We found significantly higher mRNA expression of two trypsin genes (trypsin-3 and trypsin-7) after feeding on different host plant treatments. Furthermore, the higher mRNA expression of one chymotrypsin-9 gene was observed in Corn and Rice-C treatments. Similarly, the results corroborate the higher expression of trypsin and chymotrypsin genes as reported by Brioschi et al. (2007) when S. frugiperda larvae fed on an artificial diet supplemented with soybean BowmanBirk inhibitor. Likewise, it has been shown that serine proteases were highly differentially 
regulated when $S$. frugiperda larvae fed on their primary plant (corn) and alternate host plant (rice) in a study by Silva-Brandão et al. (2017). In another polyphagous Lepidoptera pest, Helicoverpa armigera, similar mRNA expression and adaptation strategy was observed when exposed to dietary SKTI (Bown, Wilkinson and Gatehouse, 2004).

Because different host plants stimulate gene expression reconfiguration beyond those genes that encode digestive proteases, using RNAi to target plants inhibitor (PI) induces the key genes of insect digestive enzymes and other anti-defensive genes that may prevent the adaptation mechanism in destructive insect pests. Our results indicate that the knockdown of SfTry-3 and SfTry-7 genes significantly reduced the mRNA expression levels of the trypsin genes and, as a result, increased mortality. Expression levels of SfChy-9 displayed a similar trend, highlighting its potential importance, but with lower mortality in treated groups. Our results are supported by previous studies showing that the down-regulation of one serine protease gene with RNA interference leads to an increased resistance to Cry1Ac in H. armigera larvae (Liu et al., 2014). Furthermore, simultaneous down-regulation of serine protease gene by means of RNA interference, resulted in reduced capability of locust nymphs to cope with the effects of PI (Spit $e t$ al., 2016).

\section{Conclusions}

Our results indicate that $S$. frugiperda larvae rely on gut digestive physiology and related genes for host plant adaptation. We were able to explain that phenotypic plasticity and selection in response to alternative host plants for multiple generations is the product of actions of gut digestive enzymes and overexpression of related genes. Down-regulation of Sftry and Sfchy genes using RNAi confirms the mechanisms of $S$. frugiperda gut digestive enzymes in host plant adaptation. Analysis of quantitative relations between plant chemical traits such as nutrition, secondary 
metabolites and gene expression related to metabolism/detoxication opens the door for molecular research to interpret the biological mechanisms of phytophagous insect host selectivity and adaptability. However, we recognise that gut digestive proteases in host plant adaptation mechanisms need to be studied further in order to advance this as a strategy for pest control.

\section{Acknowledgments}

This work was supported by the Key R\&D Program of Zhejiang Province (2020C02003), the Shanghai Innovation Project for Agricultural Promotion (2019N3-9), and the Joint Agricultural Project between Pinghu County and Zhejiang Academy of Agricultural Sciences (PH20190002)

\section{Disclosure}

We declare we do not have any commercial or associative interest that represent a conflict of interest in connection with the work submitted. 


\section{References}

Acevedo, F. E. et al. (2018) 'Intraspecific differences in plant defense induction by fall armyworm strains', New Phytologist, 218, pp. 310-321. doi: 10.1111/nph.14981.

Assefa, Y. (2019) 'Molecular identification of the invasive strain of Spodoptera frugiperda (JE smith) (Lepidoptera: Noctuidae) in Swaziland', International Journal of Tropical Insect Science, 39, pp. 73-78. doi: 10.1007/s42690-01900018-5.

Beaumont, M. A. and Balding, D. J. (2004) 'Identifying adaptive genetic divergence among populations from genome scans', Molecular Ecology, 13, pp. 969-980. doi: 10.1111/j.1365-294X.2004.02125.x.

Becerra, J. X. (2015) 'On the factors that promote the diversity of herbivorous insects and plants in tropical forests', Proceedings of the National Academy of Sciences of the United States of America, 112, pp. 6098-6103. doi: 10.1073/pnas.1418643112.

Bennett, M. et al. (2020) 'Barriers to Efficient Foliar Uptake of dsRNA and Molecular Barriers to dsRNA Activity in Plant Cells', Frontiers in Plant Science. doi: 10.3389/fpls.2020.00816.

Berenbaum, M. and Neal, J. J. (1985) 'Synergism between myristicin and xanthotoxin, a naturally cooccurring plant toxicant', Journal of Chemical Ecology, 11, pp. 1349-1358. doi: 10.1007/BF01012136.

Borzoui, E., Naseri, B. and Rahimi Namin, F. (2015) 'Different diets affecting biology and digestive physiology of the Khapra beetle, Trogoderma granarium Everts (Coleoptera: Dermestidae)', Journal of Stored Products Research, 62, pp. 1-7. doi: 10.1016/j.jspr.2015.03.003.

Bown, D. P., Wilkinson, H. S. and Gatehouse, J. A. (2004) 'Regulation of expression of genes encoding digestive proteases in the gut of a polyphagous lepidopteran larva in response to dietary protease inhibitors', in Physiological Entomology, pp. 278-290. doi: 10.1111/j.0307-6962.2004.00402.x.

Brioschi, D. et al. (2007) 'General up regulation of Spodoptera frugiperda trypsins and chymotrypsins allows its adaptation to soybean proteinase inhibitor', Insect Biochemistry and Molecular Biology, 37, pp. 1283-1290. doi: 10.1016/j.ibmb.2007.07.016.

Butterworth, M. H. (1963) 'Digestibility trials on forages in Trinidad and their use in the prediction of nutritive value', The Journal of Agricultural Science, 60, pp. 341-346. doi: 10.1017/S0021859600011928.

Del Campo, M. L. et al. (2001) 'Host recognition by the tobacco hornworm is mediated by a host plant compound', Nature, 411, pp. 186-189. doi: 10.1038/35075559.

Cantón, P. E. and Bonning, B. C. (2020) 'Transcription and Activity of Digestive Enzymes of Nezara viridula Maintained on Different Plant Diets', Frontiers in Physiology, 10, p. 1553. doi: 10.3389/fphys.2019.01553.

Carvalho, R. A. et al. (2013) 'Investigating the Molecular Mechanisms of Organophosphate and Pyrethroid Resistance in the Fall Armyworm Spodoptera frugiperda', PLOS ONE, 8, p. e62268. doi: 10.1371/journal.pone.0062268.

Chen, X. et al. (2019) 'Fitness costs of Vip3A resistance in Spodoptera frugiperda on different hosts', Pest Management Science, 75, pp. 1074-1080. doi: 10.1002/ps.5218.

Dermauw, W. et al. (2013) 'A link between host plant adaptation and pesticide resistance in the polyphagous spider mite Tetranychus urticae', Proceedings of the National Academy of Sciences. doi: 10.1073/pnas.1213214110.

Dunse, K. M. et al. (2010) 'Molecular basis for the resistance of an insect chymotrypsin to a potato type II proteinase inhibitor', Proceedings of the National Academy of Sciences of the United States of America, 107, pp. 15016-15021. doi: 10.1073/pnas.1009327107.

Ehrlich, P. R. and Raven, P. H. (1964) 'Butterflies and Plants: A Study in Coevolution', Evolution, 18, pp. 586-608. doi: $10.2307 / 2406212$.

Fischer, D. C., Kogan, M. and Paxton, J. (1990) 'Effect of glyceollin, a soybean phytoalexin, on feeding by three phytophagous beetles (Coleoptera: Coccinellidae and Chrysomelidae): Dose versus response', Environmental Entomology, 19, pp. 1278-1282. doi: 10.1093/ee/19.5.1278.

Forister, M. L. et al. (2012) 'Revisiting the evolution of ecological specialization, with emphasis on insect-plant interactions', Ecology, 93, pp. 981-91. doi: 10.1890/11-0650.1.

Foss, L. K. and Rieske, L. K. (2003) 'Species-specific differences in oak foliage affect preference and performance of gypsy moth caterpillars', Entomologia Experimentalis et Applicata, 108, pp. 87-93. doi: 10.1046/j.15707458.2003.00067.x.

Futuyma, D. J. and Agrawal, A. A. (2009) 'Macroevolution and the biological diversity of plants and herbivores', Proceedings of the National Academy of Sciences of the United States of America. doi: 10.1073/pnas.0904106106.

Gatehouse, L. N. et al. (1998) 'Characterization of major midgut proteinase cDNAs from Helicoverpa armigera larvae and changes in gene expression in response to four proteinase inhibitors in the diet', Insect Biochemistry and Molecular Biology, 27, pp. 929-944. doi: 10.1016/S0965-1748(97)00074-X.

Ginting, S. et al. (2020) 'New invasive pest, spodoptera frugiperda (J. e. smith) (lepidoptera: Noctuidae) attacking corn in bengkulu, indonesia', Serangga. 
Goergen, G. et al. (2016) 'First report of outbreaks of the fall armyworm spodoptera frugiperda (J E Smith) (Lepidoptera, Noctuidae), a new alien invasive pest in West and Central Africa', PLoS ONE, 11, p. e0165632. doi: 10.1371/journal.pone.0165632.

Golikhajeh, N., Naseri, B. and Razmjou, J. (2017) 'Geographic origin and host cultivar influence on digestive physiology of spodoptera exigua (Lepidoptera: Noctuidae) larvae', Journal of Insect Science, 12, pp. 1-8. doi: $10.1093 /$ jisesa/iew 104 .

Gouin, A. et al. (2017) 'Two genomes of highly polyphagous lepidopteran pests (Spodoptera frugiperda, Noctuidae) with different host-plant ranges', Scientific Reports, 7, p. 11816. doi: 10.1038/s41598-017-10461-4.

Groot, A. T. et al. (2010) 'The roles and interactions of reproductive isolation mechanisms in fall armyworm (Lepidoptera: Noctuidae) host strains', Ecological Entomology, 35, pp. 105-118. doi: 10.1111/j.13652311.2009.01138.x.

Guan, R., Li, H. and Miao, X. (2017) 'RNAi pest control and enhanced BT insecticidal efficiency achieved by dsRNA of chymotrypsin-like genes in Ostrinia furnacalis', Journal of Pest Science, 90, pp. 745-757. doi: 10.1007/s10340016-0797-9.

Hafeez, M. et al. (2019) 'Knock-down of gossypol-inducing cytochrome p450 genes reduced deltamethrin sensitivity in spodoptera exigua (hübner)', International Journal of Molecular Sciences, 20, p. 2248. doi: 10.3390/ijms20092248. Herde, M. and Howe, G. A. (2014) 'Host plant-specific remodeling of midgut physiology in the generalist insect herbivore Trichoplusia ni', Insect Biochemistry and Molecular Biology, 50, pp. 58-67. doi: 10.1016/j.ibmb.2014.03.013.

Herrero, S. et al. (2005) 'Identification and recombinant expression of a novel chymotrypsin from Spodoptera exigua', Insect Biochemistry and Molecular Biology, 35, pp. 1073- 1082. doi: 10.1016/j.ibmb.2005.05.006.

Huang, X. et al. (2017) 'Diet alters performance and transcription patterns in Oedaleus asiaticus (Orthoptera: Acrididae) grasshoppers', PLOS ONE, 12, p. e0186397. doi: 10.1371/journal.pone.0186397.

Juma, G., Le Ru, B. and Calatayud, P.-A. (2019) 'Assortments of Digestive Enzymes Induced in First Instar Larvae of Busseola fusca Feeding on Different Plants', International Journal of Insect Science, 11, pp. 1-6. doi: $10.1177 / 1179543319843521$.

Kumar, M. S. et al. (2016) 'Insecticides induced biochemical changes in freshwater microalga Chlamydomonas mexicana', Environmental Science and Pollution Research, 23, pp. 1091-1099. doi: 10.1007/s11356-015-4681-6.

$\mathrm{Li}$, X. J. et al. (2020) 'Prediction of migratory routes of the invasive fall armyworm in eastern China using a trajectory analytical approach', Pest Management Science, 76, pp. 454-463. doi: 10.1002/ps.5530.

Lim, Z. X. et al. (2016) 'Diet-delivered RNAi in Helicoverpa armigera - Progresses and challenges', Journal of Insect Physiology, pp. 86-93. doi: 10.1016/j.jinsphys.2015.11.005.

Lin, H. et al. (2015) 'Genome-wide identification and expression profiling of serine proteases and homologs in the diamondback moth, Plutella xylostella (L.)', BMC Genomics, 16, p. 1054. doi: 10.1186/s12864-015-2243-4.

Liu, C. et al. (2014) 'Cis-mediated down-regulation of a trypsin gene associated with Bt resistance in cotton bollworm', Scientific Reports, 4, p. 7219. doi: 10.1038/srep07219.

Liu, H. W. et al. (2017) 'A midgut-specific serine protease, BmSP36, is involved in dietary protein digestion in the silkworm, Bombyx mori', Insect Science, 24, pp. 753-76. doi: 10.1111/1744-7917.12369.

Livak, K. J. and Schmittgen, T. D. (2001) 'Analysis of relative gene expression data using real-time quantitative PCR and the 2(-Delta Delta C(T)) Method.', Methods (San Diego, Calif.). doi: 10.1006/meth.2001.1262.

Lomate, P. R. and Bonning, B. C. (2016) 'Distinct properties of proteases and nucleases in the gut, salivary gland and saliva of southern green stink bug, Nezara viridula', Scientific Reports, 6, p. 27587. doi: 10.1038/srep27587.

Lomate, P. R. and Hivrale, V. K. (2013) 'Effect of Bacillus thuringiensis (Bt) Cry1 Ac toxin and protease inhibitor on growth and development of Helicoverpa armigera (Hübner)', Pesticide Biochemistry and Physiology, 2, pp. 77-83. doi: 10.1016/j.pestbp.2013.01.002.

Machado, V. et al. (2008) 'Molecular Characterization of Host Strains of Spodoptera frugiperda (Lepidoptera: Noctuidae) in Southern Brazil', Annals of the Entomological Society of America, 101, pp. 619-626. doi: 10.1603/0013-8746(2008)101[619:mcohso]2.0.co;2.

Mello, C. C. and Conte, D. (2004) 'Revealing the world of RNA interference', Nature, pp. 338-342. doi: 10.1038/nature 02872 .

Nagoshi, R. N. et al. (2019) 'Genetic comparisons of fall armyworm populations from 11 countries spanning subSaharan Africa provide insights into strain composition and migratory behaviors', Scientific Reports. Springer US, 9(1), pp. 1-11. doi: 10.1038/s41598-019-44744-9.

Nawaz, H. et al. (2018) 'Phytochemical Composition: Antioxidant Potential and Biological Activities of Corn', in Corn - Production and Human Health in Changing Climate, p. DOI: 10.5772/intechopen.79648. doi: 10.5772/intechopen.79648. 
de Oliveira, C. F. R. et al. (2013) 'Insensitive trypsins are differentially transcribed during Spodoptera frugiperda adaptation against plant protease inhibitors', Comparative Biochemistry and Physiology - B Biochemistry and Molecular Biology, 165, pp. 19-25. doi: 10.1016/j.cbpb.2013.02.008.

Renwick, J. A. A. (1994) 'Host-plant selection by phytophagous insects', Plant Science, 2, pp. 1-312. doi: 10.1016/0168-9452(94)90025-6.

Rivera-Vega, L. J. et al. (2017) 'Host plant driven transcriptome plasticity in the salivary glands of the cabbage looper (Trichoplusia ni)', PLoS ONE, p. 12:e0182636. doi: 10.1371/journal.pone.0182636.

Rodrigues Macedo, M. L. et al. (2003) 'A trypsin inhibitor from Peltophorum dubium seeds active against pest proteases and its effect on the survival of Anagasta kuehniella (Lepidoptera: Pyralidae)', Biochimica et Biophysica Acta - General Subjects, 1621, pp. 170-182. doi: 10.1016/S0304-4165(03)00055-2.

Rodríguez-Cabrera, L. et al. (2010) 'RNAi-mediated knockdown of a Spodoptera frugiperda trypsin-like serineprotease gene reduces susceptibility to a Bacillus thuringiensis Cry1Ca1 protoxin', Environmental Microbiology, 12, pp. 2894-2903. doi: 10.1111/j.1462-2920.2010.02259.x.

Saadati, F. and Bandani, A. R. (2011) 'Effects of serine protease inhibitors on growth and development and digestive serine proteinases of the Sunn pest, Eurygaster integriceps', Journal of Insect Science, 11, pp. 1-12. doi: 10.1673/031.011.7201.

Sarmini, M. and Premaratne, S. (2017) 'Yield and nutritional quality potential of three fodder grasses in the Northern region of Sri Lanka', Tropical Agricultural Research, 28, pp. 175 - 182. doi: 10.4038/tar.v28i2.8194.

Schoonhoven, L. M., Jermy, T. and van Loon, J. J. A. (1998) Insect-Plant Biology, Insect-Plant Biology. doi: 10.1007/978-1-4899-3200-6.

Shah, S. et al. (2020) 'Downregulation of chitin synthase A gene by diallyl trisulfide, an active substance from garlic essential oil, inhibits oviposition and alters the morphology of adult Sitotroga cerealella', Journal of Pest Science, 93, pp. 1097-1106. doi: 10.1007/s10340-020-01226-6.

Silva-Brandão, K. L. et al. (2017) 'Transcript expression plasticity as a response to alternative larval host plants in the speciation process of corn and rice strains of Spodoptera frugiperda', BMC Genomics, 18, p. 792. doi: 10.1186/s12864017-4170-z.

Singh, S. et al. (2020) 'Protease inhibitors: recent advancement in its usage as a potential biocontrol agent for insect pest management', Insect Science, pp. 186-201. doi: 10.1111/1744-7917.12641.

Spit, J. et al. (2016) 'Transcriptional Analysis of the Adaptive Digestive System of the Migratory Locust in Response to Plant Defensive Protease Inhibitors', Scientific Reports, 6, p. 32460. doi: 10.1038/srep32460.

Srinivasan, A., Giri, A. P. and Gupta, V. S. (2006) 'Structural and functional diversities in lepidopteran serine proteases', Cellular and Molecular Biology Letters, 11, pp. 132-154. doi: 10.2478/s11658-006-0012-8.

Terra, W. R. and Ferreira, C. (1994) 'Insect digestive enzymes: properties, compartmentalization and function', Comparative Biochemistry and Physiology -- Part B: Biochemistry and, pp. 1-62. doi: 10.1016/0305-0491(94)901414.

Tilmon, K. J. (2008) Specialization, speciation, and radiation: The evolutionary biology of herbivorous insects, Specialization, Speciation, and Radiation: The Evolutionary Biology of Herbivorous Insects. doi: 10.1653/00154040(2008)91[351:ssarte]2.0.co;2.

Vanbergen, A. J. et al. (2013) 'Threats to an ecosystem service: Pressures on pollinators', Frontiers in Ecology and the Environment, pp. 251-259. doi: 10.1890/120126.

Veenstra, K. H., Pashley, D. P. and Ottea, J. A. (1995) 'Host-Plant Adaptation in Fall Armyworm Host Strains: Comparison of Food Consumption, Utilization, and Detoxication Enzyme Activities', Annals of the Entomological Society of America, 88, pp. 80-91. doi: 10.1093/aesa/88.1.80.

Wang, W. et al. (2018) 'Rice secondary metabolites: Structures, roles, biosynthesis, and metabolic regulation', Molecules, p. 3098. doi: 10.3390/molecules23123098.

Wang, X. et al. (2018) 'Molecular identification of four novel cytochrome P450 genes related to the development of resistance of Spodoptera exigua (Lepidoptera: Noctuidae) to chlorantraniliprole', Pest Management Science. doi: $10.1002 /$ ps. 4898 .

Wang, Y. et al. (2006) 'Effect of the secondary substances from wheat on the growth and digestive physiology of cotton bollworm Helicoverpa armigera (Lepidoptera: Noctuidae)', European Journal of Entomology, 203, pp. 55258. doi: 10.14411/eje.2006.030.

Yu, S. J., Nguyen, S. N. and Abo-Elghar, G. E. (2003) 'Biochemical characteristics of insecticide resistance in the fall armyworm, Spodoptera frugiperda (J.E. Smith)', Pesticide Biochemistry and Physiology, 77, pp. 1-11. doi: 10.1016/S0048-3575(03)00079-8.

Zalucki, M. P., Clarke, A. R. and Malcolm, S. B. (2002) 'Ecology and Behavior of First Instar Larval Lepidoptera', Annual Review of Entomology, 47, pp. 361-393. doi: 10.1146/annurev.ento.47.091201.145220. 
Zhang, J. et al. (2017) 'Next-Generation Insect-Resistant Plants: RNAi-Mediated Crop Protection', Trends in Biotechnology, pp. 871-882. doi: 10.1016/j.tibtech.2017.04.009.

Zhu-Salzman, K. and Zeng, R. (2015a) 'Insect response to plant defensive protease inhibitors', Annual Review of Entomology, pp. 233-252. doi: 10.1146/annurev-ento-010814-020816.

Zhu-Salzman, K. and Zeng, R. (2015b) 'Insect Response to Plant Defensive Protease Inhibitors', Annual Review of Entomology, 60, pp. 233-252. doi: 10.1146/annurev-ento-010814-020816. 
Table 1. List of all primers used in this study

Figure 1 Graphical representation of experimental design.

Figure 2 S. frugiperda, following rearing for 11 generations on treatments of corn or rice before either remaining on the host plant (Corn, Rice), switching hosts (Corn-R, Rice-C). (A) the total enzyme activity (B) protease class-specific activity of trypsin and (C) protease class-specific activity of chymotrypsin was recorded. Synthetic substrates class: total proteases (azocasein), trypsin (BApNA) and chymotrypsin (SAAPFpNA), Statistical differences among treatments for each enzyme type are indicated with different letters indicating significant differences between groups ( $\mathrm{P} \leq 0.05$; Tukey's HSD test). Error bars represent SEM of three biological replicates.

Figure 3 Protease class-specific activity differences among the treatments for S. frugiperda. Bars indicate the rearing host plant of either Rice, Corn followed by the subsequent host ( $\mathrm{R}$ for rice, $\mathrm{C}$ for corn). Synthetic inhibitors class: trypsin (TLCK), chymotrypsin (TPCK), and serine proteases (E-64), Statistical differences among treatments for each enzyme type are indicated with different letters indicating significant differences between groups $(\mathrm{P} \leq 0.05$; Tukey's HSD test). Error bars represent SEM of three biological replicates.

Figure 4. Single and combined effects of enzymes specific inhibitors on the mortality of S. frugiperda larvae. Following the feeding on an artificial diet supplemented with $2 \%$ enzymes specific inhibitors and an artificial diet without inhibitors for $24 \mathrm{~h}$ the exposed larvae were transferred into the pots containing different host plants treatments for $72 \mathrm{~h}$. Data shown are means \pm SEM derived from three biological replicates. Different letters above bars indicate significant differences $(\mathrm{P}<0.05)$ according to the Tukey's HSD test.

Figure 5. Single and combined effects of enzyme-specific inhibitors on the larval weight of $S$. frugiperda. Following the feeding on an artificial diet supplemented with $2 \%$ enzymes specific inhibitors and an artificial diet without inhibitors for $24 \mathrm{~h}$, the exposed larvae were transferred into the pots containing different host plants treatments for 72 h. Data shown are means \pm SEM derived from three biological replicates. Different letters above bars indicate significant differences $(\mathrm{P}<0.05)$ according to the Tukey's HSD test.

Figure 6. (A) qRT-PCR gene expression analyses of $S$. frugiperda trypsin genes and (B) qRT-PCR gene expression analyses of $S$. frugiperda chymotrypsin genes on different treatments of host plants. Where Corn-R indicates larvae transferred from corn to rice after 11 generations and Rice-C indicates larvae transferred from rice to corn after 11 generations.

Figure 7 Down-regulation of dsSftry-3 (A), dsSftry-7 (B) and dsSfchym-9 (C) or dsRED (control) genes in $S$. frugiperda larvae. The droplet-feeding of dsSftry-3, dsSftry-7 and dsSFchym-9 or dsRED on an artificial diet for 24 $\mathrm{h}$ the exposed larvae were transferred into the pots containing different host plants treatments for $72 \mathrm{~h}$ before qRTPCR analysis. Where Corn-R indicates larvae transferred from corn to rice after 11 generations and Rice-C indicates larvae transferred from rice to corn after 11 generations. Data shown are means \pm SEM derived from three biological replicates. Different letters above bars indicate significant differences $(\mathrm{P}<0.05)$ according to the Tukey's HSD test.

Figure 8 Effect of dsSftry-3, dsSftry-7 and dsSFchym-9 or dsRED (control) on (A) the larval mortality and (B) larval weight of S. frugiperda. The droplet-feeding of dsSftry-3, dsSftry-7 and dsSFchym-9 or dsRED on an artificial diet for $24 \mathrm{~h}$ the exposed larvae were transferred into the pots containing different host plants treatments for $72 \mathrm{~h}$ for mortality and larval weight analysis. Where Corn- $\mathrm{R}$ indicates larvae transferred from corn to rice after 11 generations and Rice-C indicates larvae transferred from rice to corn after 11 generations. Data shown are means \pm SEM derived from three biological replicates. Different letters above bars indicate significant differences $(\mathrm{P}<0.05)$ according to the Tukey's HSD test. 
2 Table 1. List of all primers used in this study

\begin{tabular}{|c|c|c|c|c|}
\hline $\begin{array}{l}\text { Primers used for } \\
\text { qRT-PCR }\end{array}$ & Sense primers & Anti-sense primers & Size of the amplicon & PCR Efficiency (\%) \\
\hline SfTry3 & 5'-ACGTCCATTGACAAGTTCCC-3' & 5'-CGGTAGCTTGGGTCGTAGAA-3' & 157 & 98 \\
\hline SfTry4 & 5'-AACTTATGGCGGCTAGCGTA-3' & 5'-AAGGGACCTCCGAAGTCACC-3' & 127 & 102 \\
\hline SfTry5 & 5'-CAGAGGATTGTGGGTGGTTC-3' & 5'-TGGGCAGCAGTAAGGATAGC-3' & 143 & 92 \\
\hline SfTry7 & -F 5'-TCGAGAATTACCCCAGCATC-3' & 5'-AGGTACCGGCTCTGATACGA-3' & 162 & 105 \\
\hline SfTry8 & 5'- TCAACGTTGTGGCGGTATCA-3' & 5'- GAAAGAAGAGCCCACACGGA-3' & 112 & 99 \\
\hline SfTry9 & 5'- GTCCTCTCTACCACAACGGC-3' & 5'- GAGATCCAGGCAGTGTAGCG-3' & 115 & 100 \\
\hline SfChy 1 & 5'-AAGTCATCATGCACCCACAA-3' & 5'-GACACGTGGCTTACCACAGA-3' & 136 & 100 \\
\hline SfChy2 & 5'-CGTCTCAGGAAAACCCAGTC-3' & 5'-AGGGACGTTGGAAATGTCAG-3' & 118 & 103 \\
\hline SfChy3 & 5'-ТTCCTTCCCCCTTATCGTTC-3' & 5'-CAAGAGAGGGCTGTTGTTCC-3' & 142 & 94 \\
\hline SfChy5 & 5'-TTACCGCTAACCGTGTGCTT-3' & 5'-CGATGACATCTGACAAGGCG-3' & 222 & 91 \\
\hline SfChy7 & 5'-TTCCTGAGCCACGTTAGCTT-3' & 5'-CAAGACAGGCTCGTTGTTGA-3' & 171 & 100 \\
\hline SfChy9 & 5'-GGATCTCAGCTCGGAGAAAA-3' & 5'-GCAAGAGGACCACCAGAGTC-3' & 236 & 90 \\
\hline $\mathrm{S} 30$ & 5'- AGCGATTCTGACAGTGTGGG-3' & 5'- AACCGTGGACTTTACCACCG-3' & 119 & ---- \\
\hline GAPDH & 5'-CGGTGTCTTCACAACCACAG-3' & 5'-TTGACACCAACGACGAACAT-3' & 111 & ---- \\
\hline
\end{tabular}

3

4

5 


\begin{tabular}{ccc}
\hline Primers used for RNAi & Sense primers & Anti-sense primers \\
\hline \multirow{2}{*}{ dsSfTry3 } & 5'-ggatcctaatacgactcactatagg & 5'-ggatcctaatacgactcactatagg \\
& ATGGCAGTACTGGCTCTCCTG-3' & TTAGTTGACAGAAGCAGCGATC-3' \\
dsSfTry7 & 5'-ggatcctaatacgactcactatagg & 5'-ggatcctaatacgactcactatagg \\
& ATGCGGTCCCAAACCGCATTG-3' & TTACAGAGAGGAAACAGTTTGTAC-3 \\
dsSfChy9 & 5'-ggatcctaatacgactcactatagg & 5'-ggatcctaatacgactcactatagg \\
& CTCCGCAAGGCACATCACTC-3' & GAATTGCCTTCGCATCCACC-3' \\
dsRED & 5'-ggatcctaatacgactcactatagg & 5'-ggatcctaatacgactcactatagg \\
& GCAAGCTATGCATCCAACGCGTTGGG-3' & CAAGCTATGCATCCAACGCGTTGGGG-3' \\
\hline
\end{tabular}


Corn-population at $11^{\text {th }}$ generation (Corn)

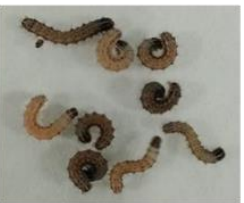

14

15

21

22 Figure 1 Graphical representation of experimental design.

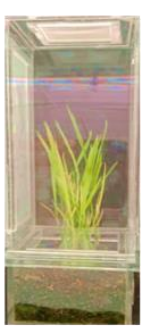

Rice Plants

Corn plants (Corn)

Fall armyworm larvae reared on corn plants for 11 generations and transferred on rice plants

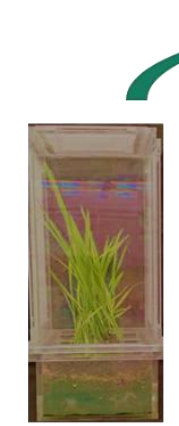

Rice plants (Rice)
Fall armyworm larvae reared on rice plants for 11 generations and transferred on corn plants

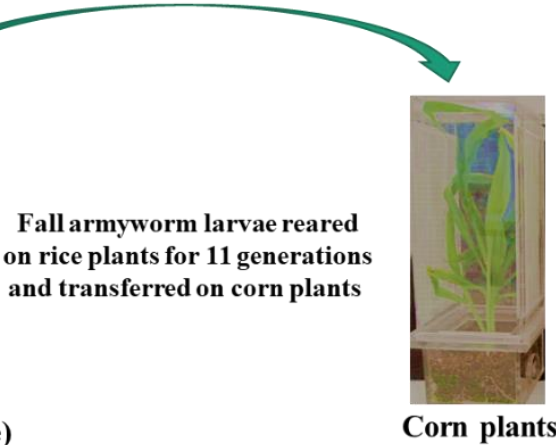

Corn plants
Rice-C 16

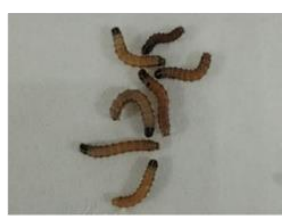

20 

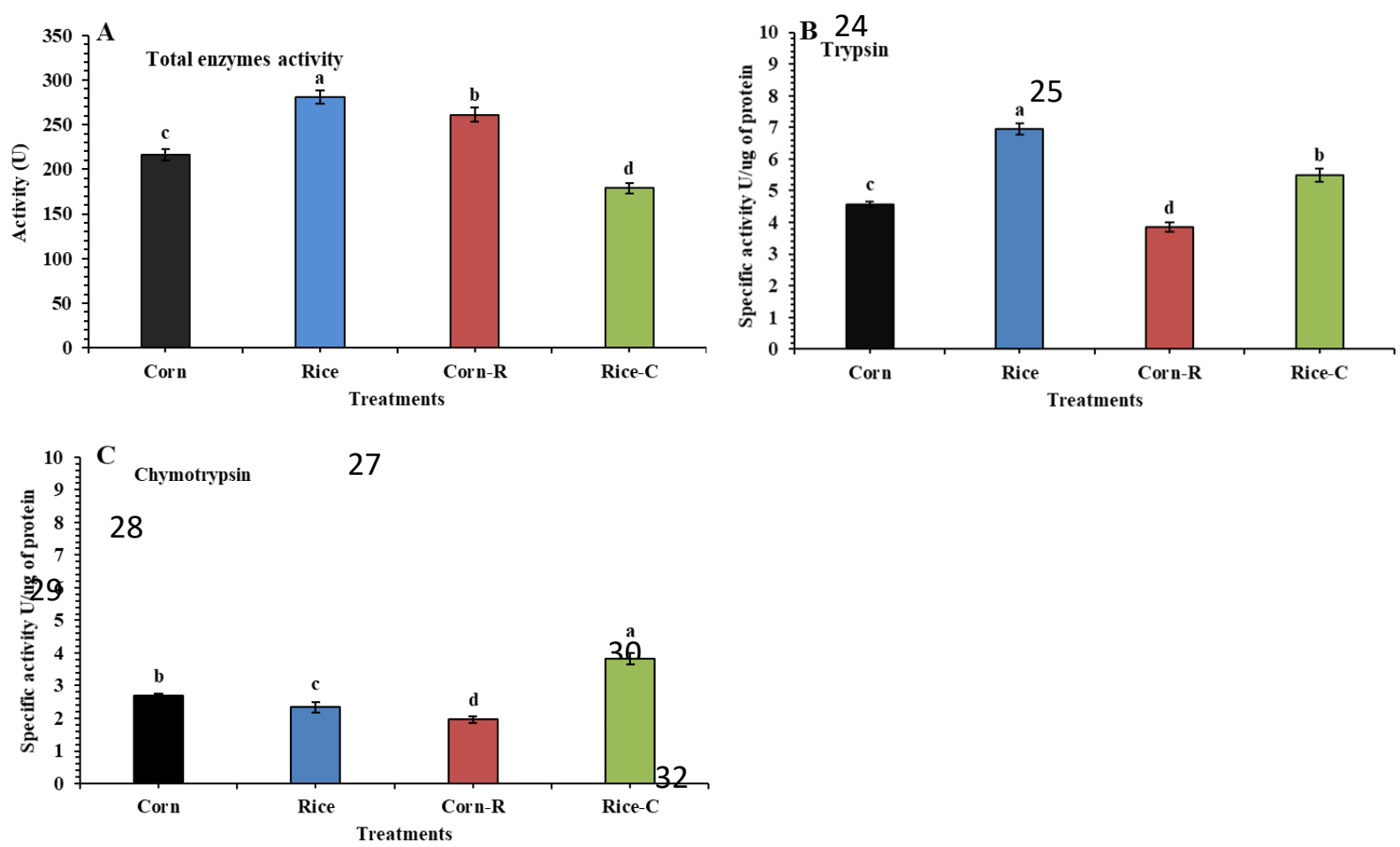

Figure 2 S. frugiperda, following rearing for 11 generations on treatments of corn or rice before either remaining on the host plant (Corn, Rice), switching hosts (Corn-R, Rice-C). (A) the total enzyme activity (B) protease class-specific activity of trypsin and (C) protease class-specific activity of chymotrypsin was recorded. Synthetic substrates class: total proteases (azocasein), trypsin (BApNA) and chymotrypsin (SAAPFpNA), Statistical differences among treatments for each enzyme type are indicated with different letters indicating significant differences between groups ( $\mathrm{P} \leq 0.05$; Tukey's HSD test). Error bars represent SEM of three biological replicates. 


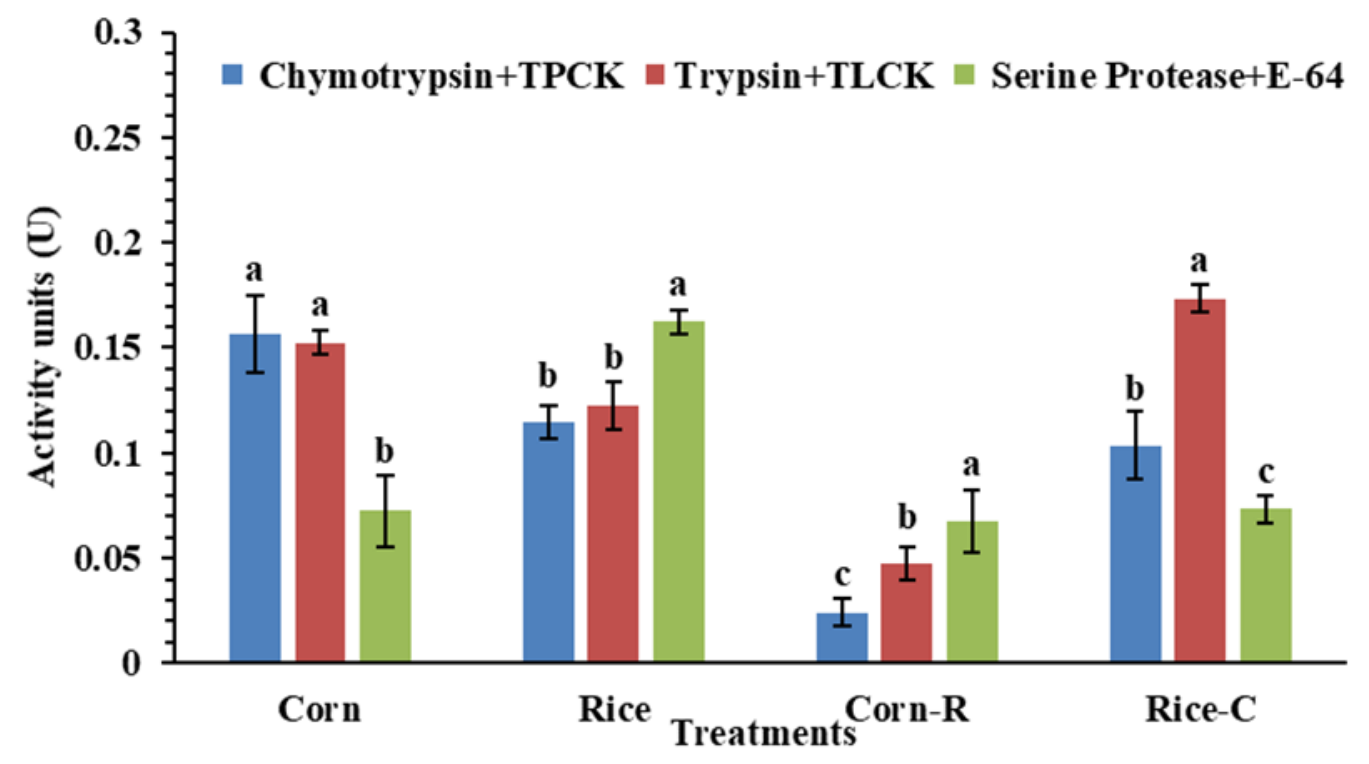

Figure 3 Protease class-specific activity differences among the treatments for S. frugiperda. Bars indicate the rearing 53 host plant of either Rice, Corn followed by the subsequent host ( $\mathrm{R}$ for rice, $\mathrm{C}$ for corn). Synthetic inhibitors class: 54 trypsin (TLCK), chymotrypsin (TPCK), and serine proteases (E-64), Statistical differences among treatments for each 55 enzyme type are indicated with different letters indicating significant differences between groups $(\mathrm{P} \leq 0.05$; Tukey's 56 HSD test). Error bars represent SEM of three biological replicates.

57

58 

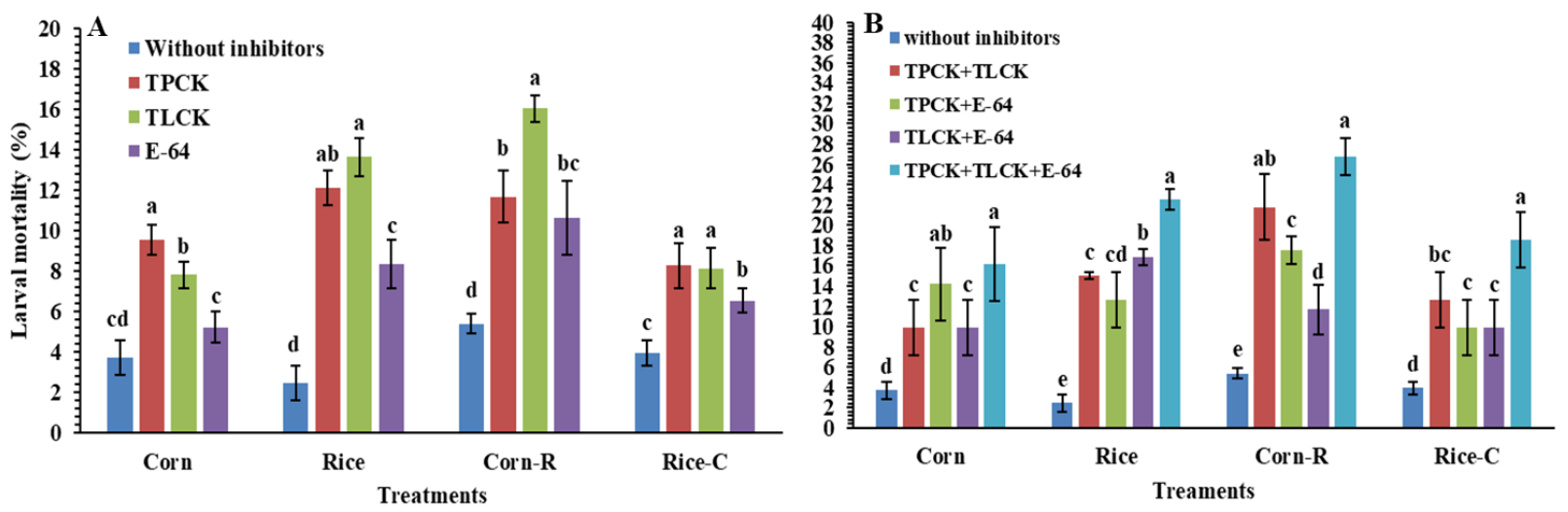

Figure 4. Single and combined effects of enzymes specific inhibitors on the mortality of S. frugiperda larvae. Following the feeding on an artificial diet supplemented with $2 \%$ enzymes specific inhibitors and an artificial diet without inhibitors for $24 \mathrm{~h}$ the exposed larvae were transferred into the pots containing different host plants treatments for $72 \mathrm{~h}$. Data shown are means \pm SEM derived from three biological replicates. Different letters above bars indicate significant differences $(\mathrm{P}<0.05)$ according to the Tukey's HSD test. 

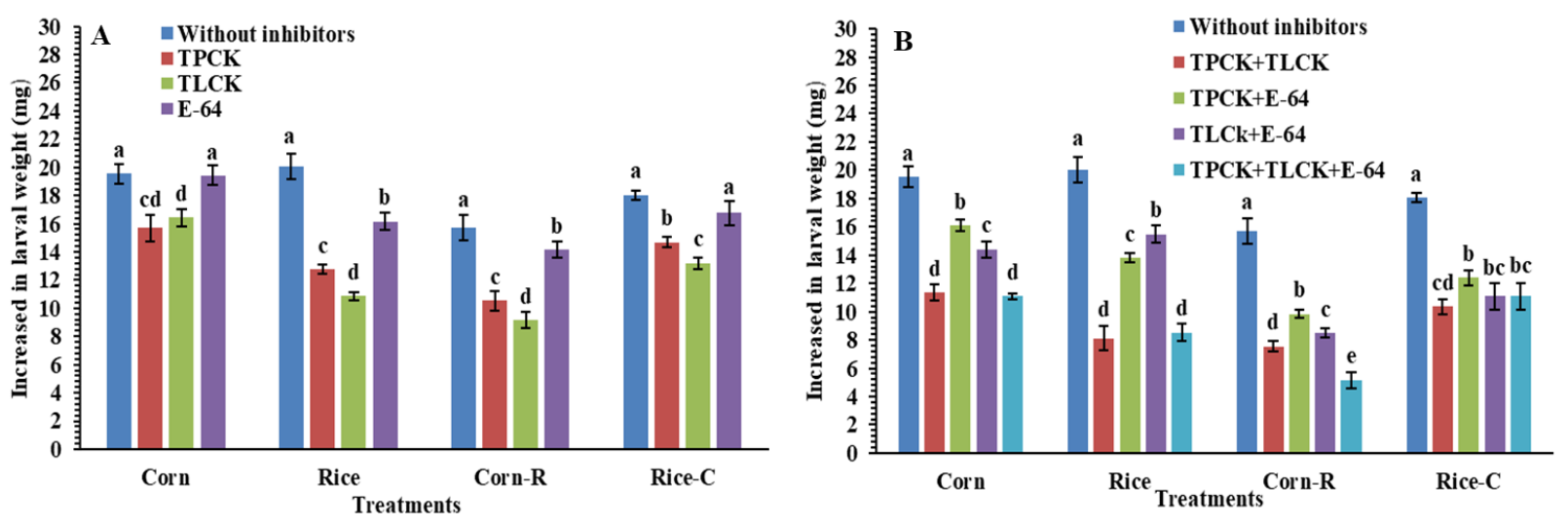

Figure 5. Single and combined effects of enzyme-specific inhibitors on the larval weight of $S$. frugiperda. Following the feeding on an artificial diet supplemented with $2 \%$ enzymes specific inhibitors and an artificial diet without inhibitors for $24 \mathrm{~h}$, the exposed larvae were transferred into the pots containing different host plants treatments for 72 h. Data shown are means \pm SEM derived from three biological replicates. Different letters above bars indicate significant differences $(\mathrm{P}<0.05)$ according to the Tukey's HSD test. 

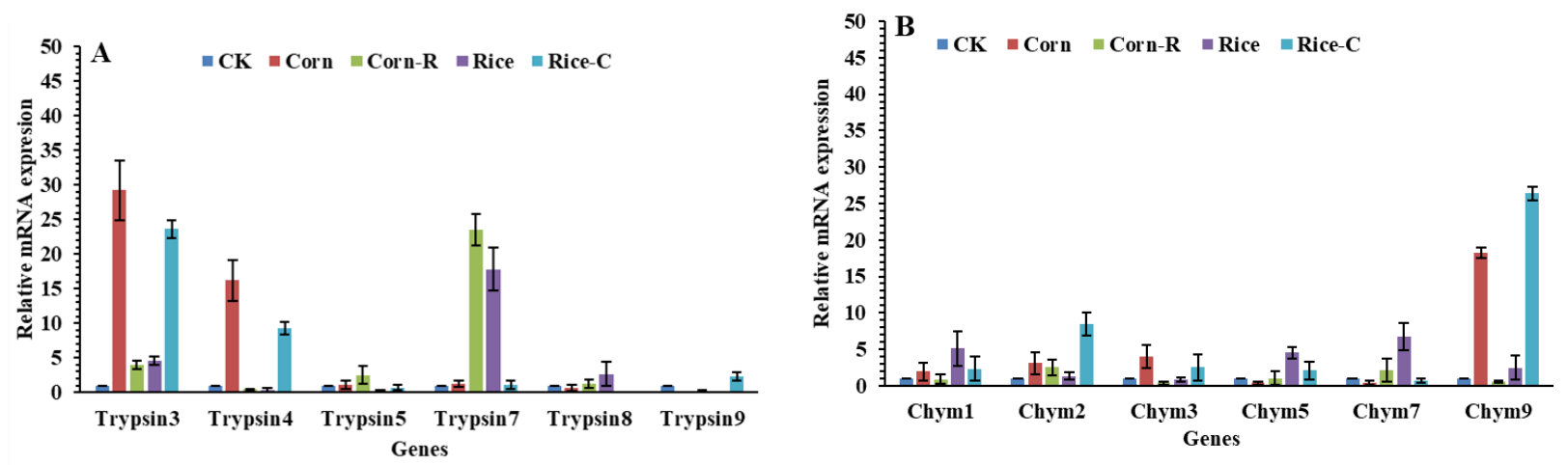

71 Figure 6. (A) qRT-PCR gene expression analyses of $S$. frugiperda trypsin genes and (B) qRT-PCR gene expression

72 analyses of $S$. frugiperda chymotrypsin genes on different treatments of host plants. Where Corn-R indicates larvae

73 transferred from corn to rice after 11 generations and Rice-C indicates larvae transferred from rice to corn after 11

74 generations.

75 

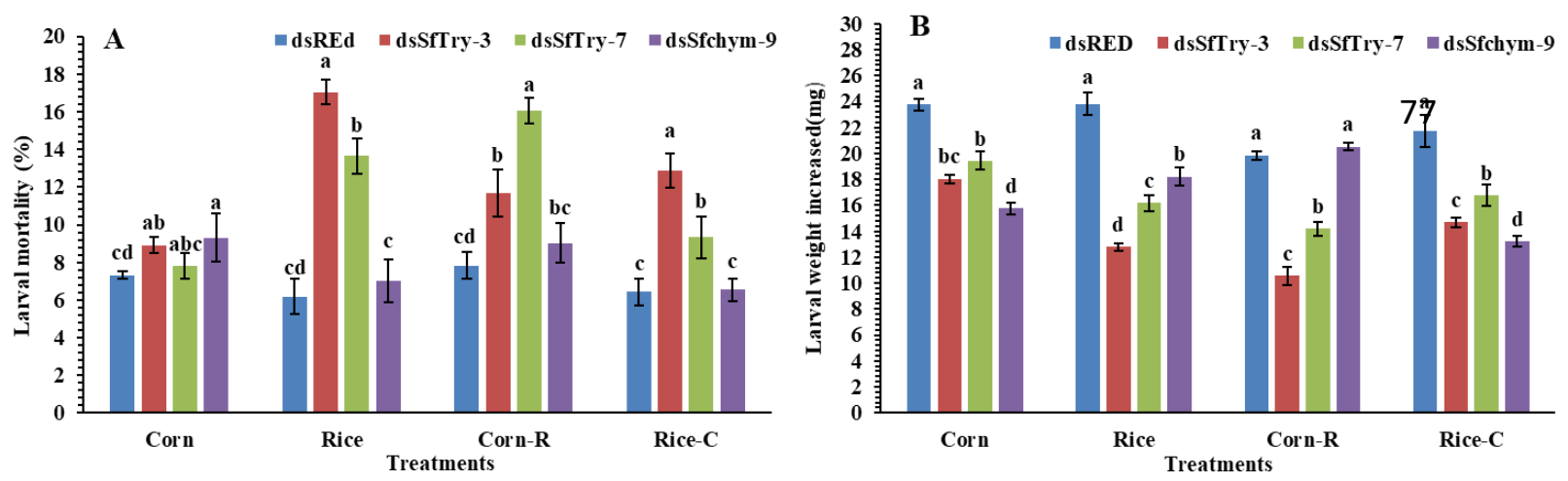

Figure 7 Effect of dsSftry-3, dsSftry-7 and dsSFchym-9 or dsRED (control) on (A) the larval mortality and (B) larval weight of $S$. frugiperda. The droplet-feeding of dsSftry-3, dsSftry-7 and dsSFchym-9 or dsRED on an artificial diet for $24 \mathrm{~h}$ the exposed larvae were transferred into the pots containing different host plants treatments for $72 \mathrm{~h}$ for mortality and larval weight analysis. Where Corn- $\mathrm{R}$ indicates larvae transferred from corn to rice after 11 generations and Rice-C indicates larvae transferred from rice to corn after 11 generations. Data shown are means \pm SEM derived from three biological replicates. Different letters above bars indicate significant differences $(\mathrm{P}<0.05)$ according to the Tukey's HSD test. 

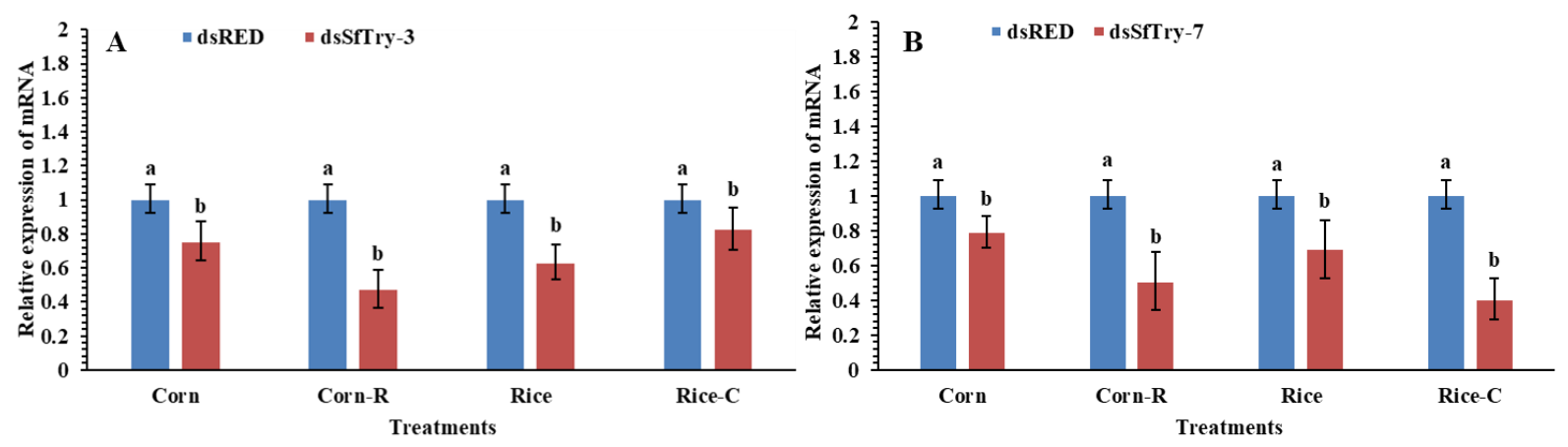

94

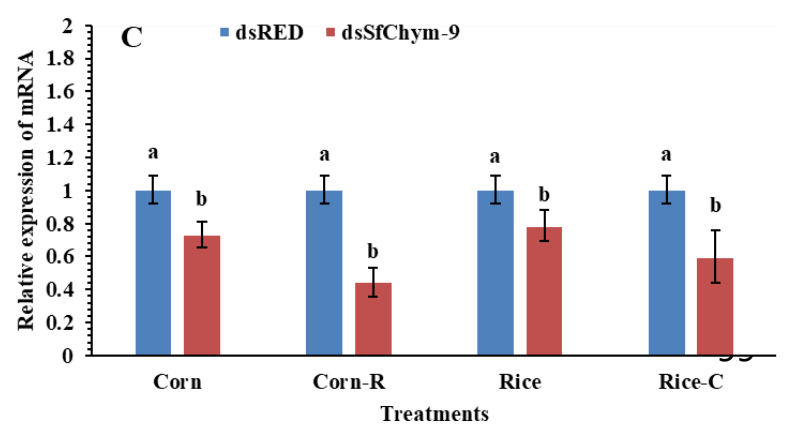

101 Figure 8 Down-regulation of dsSftry-3 (A), dsSftry-7 (B) and dsSfchym-9 (C) or dsRED (control) genes in $S$. frugiperda larvae. The droplet-feeding of dsSftry-3, dsSftry-7 and dsSFchym-9 or dsRED on an artificial diet for 24 $\mathrm{h}$ the exposed larvae were transferred into the pots containing different host plants treatments for $72 \mathrm{~h}$ before qRTPCR analysis. Where Corn-R indicates larvae transferred from corn to rice after 11 generations and Rice-C indicates larvae transferred from rice to corn after 11 generations. Data shown are means \pm SEM derived from three biological replicates. Different letters above bars indicate significant differences $(\mathrm{P}<0.05)$ according to the Tukey's HSD test. 